\title{
A meta-analysis of weekly cisplatin versus three weekly cisplatin chemotherapy plus concurrent radiotherapy (CRT) for advanced head and neck cancer (HNC)
}

\author{
Jian Guan ${ }^{1, *}$, Yue Zhang ${ }^{1, *}$, Qinyang Li $^{1}$, Yaowei Zhang ${ }^{1}$, Lu Li ${ }^{1}$, Min Chen ${ }^{1}$, Nanjie \\ Xiao $^{1}$, Longhua Chen ${ }^{1}$ \\ ${ }^{1}$ Department of Radiation Oncology, Nanfang Hospital, Southern Medical University, Guangzhou, China \\ *These authors have contributed equally to this work \\ Correspondence to: Jian Guan, email: guanjian5461@163.com \\ Longhua Chen, email: chenlh5461@163.com \\ Keywords: cisplatin, head and neck, cancer, therapy, meta-analysis
}

Received: January 11,2016 Accepted: August 22, $2016 \quad$ Published: September 02, 2016

\section{ABSTRACT}

Purpose: This study was performed to compare the efficacies and acute toxicities in weekly- and three weekly- cisplatin based concurrent chemoradiotherapy (CCRT) for advanced HNC patients.

Results: 779 patients of 10 studies were eligible. No difference in the 2-, 3-year OS or 1-, 2-year LRFS was observed, whereas patients in three weekly CCRT arm tended to have a better 5-year OS ( $H R=1.79,95 \%$ C 0.97-3.31, $p=0.06)$. Weekly arm seemed to show less gastrointestinal toxicities ( $R R=0.59,95 \% C I \quad 0.34-1.02, p=0.06$ ), but similar hematologic toxicity compared to three weekly arm. Subgroup analysis displayed more grade $\geq 3$ mucositis $(R R=1.72, p=0.01)$, and more chemotherapy related delay/interrupt $(R R=2.68, p<0.0001)$ in weekly arm for non-nasopharynx carcinoma (non-NPC) HNC.

Methods: We conducted the meta-analysis by searching PubMed, MEDLINE, ScienceDirect, Cochrane Library and China National Knowledge Infrastructure (CNKI) databases. The primary endpoint was overall survival (OS) with secondary endpoints locoregional recurrence-free survival (LRFS) and grade $\geq 3$ acute adverse events. RevMan 5.2 was used to perform statistical analyses.

Conclusions: Three weekly cisplatin-based CCRT might achieve a higher longterm OS with no significant difference in a shorter OS and LRFS. Weekly arm was associated with less gastrointestinal toxicities but more grade $\geq 3$ mucositis and chemotherapy related delay/interrupt. Large randomized trials were urgent to further define superiority of these two regimens.

\section{INTRODUCTION}

Concurrent platinum-based chemoradiation is currently the most widely used regiment for advanced $\mathrm{HNC}$, which provides a significant improvement in 5-year OS compared with radiotherapy alone [1-3]. A $100 \mathrm{mg} / \mathrm{m}^{2}$ dose of cisplatin administered once every 3 weeks is the preferred therapeutic regimen as category 1 in NCCN Guidline of head and neck cancers (Version 1.2015 ), achieving $71 \%$ complete response (CR) rate and $34 \%$ 4-year survival [4]. But its high emetic potential, hepatotoxicity and nephrotoxicity demand further efforts be made towards improving its therapeutic and toxicity profiles. Various alternative dosing schedules were adopted to deliver cisplatin with concurrent radiotherapy to improve compliance and the toxicity profile. Among these regimens, weekly cisplatin doses ranging from 30 to $40 \mathrm{mg} / \mathrm{m}^{2}$ were used most widely, with a CR rate of $80.5 \%$ and 3-year OS of $62 \%$ [5].

Multiple studies compared the outcomes of the weekly and three-weekly cisplatin-based CCRT in advanced HNC. A randomized control trial was conducted for patients with advanced oral squamous cell carcinoma, showing higher compliance and lower acute toxicity in three-weekly arm [6]. Though another retrospective study showed statistically similar response rates and toxicities between the two arms 
in patients with stage III/IV head and neck squamous cell carcinoma (HNSCC) [7]. Several other studies also compared the efficacies and toxicities in the two regimens, but none of those were sufficiently to demonstrate the priority of the two schedules in cisplatin as part of CCRT for SCCHN. Therefore, we performed this meta-analysis to provide an assessment on survivals and adverse effects between the different cisplatin schedules for HNC patients.

\section{RESULTS}

\section{Description of studies}

The preliminary literature screening yielded 3950 records from the five databases. Finally 10 studies [6-15] of 779 patients (376 in weekly cisplatin group and 403 in three weekly group, respectively) were eligible for the meta-analysis published from 2006 to 2014. Almost all patients were stage II-IVb disease with head and neck cancer. Seven studies of enrolled were mainly mentioned of non-nasopharyngeal carcinoma (non-NPC) [6-11, 14], and the other three of all patients were diagnosed with nasopharyngeal carcinoma (NPC) [12-13, 15]. The retrieval flow was performed in the Figure 1. The main characteristics of the included studies were listed in the Table 1.

\section{Effects of interventions}

Survival events

Overall survival

Six studies [6-7, 9, 13-15] reported the data of OS, which included 267 patients in the weekly group and 263 patients in the three weekly group. Not all of the year-OS data were reported or extractable from all of the included studies. Similar outcome of 2-year OS was observed in the two arms with a HR of 1.05 including 530 eligible patients $(95 \% \mathrm{CI} 0.61-1.81, \mathrm{p}=0.85)$, as well as 3 -year OS with a HR of 1.12 including 480 eligible patients (95\%CI 0.68-1.85; $\mathrm{P}=0.65$ ) (Figure 2). Patients in three weekly regimens tended to have a better 5-year OS despite the difference had not yet reached the statistical level $(\mathrm{HR}=1.79,95 \% \mathrm{C} 0.97-3.31, \mathrm{p}=0.06)$ (Figure 2$)$. Further subgroup analysis displayed no significant difference between the two interventions either for NPC (2-OS: $\mathrm{HR}=0.54$, 95\%CI $0.15-1.90, \mathrm{p}=0.34 ; 3-\mathrm{OS}: \mathrm{HR}=0.69$, $95 \%$ CI $0.23-2.10, \mathrm{p}=0.51)[13,15]$ or non-NPC patients (2-OS: $\mathrm{HR}=1.23,95 \% \mathrm{CI} \quad 0.67-2.23, \mathrm{p}=0.51$; 3-OS: $\mathrm{HR}=1.27,95 \%$ CI $0.72-2.22, \mathrm{p}=0.41)[6-7,9,14]$ in terms of 2- and 3-year OS. There was no heterogeneity between studies for the OS analyses.

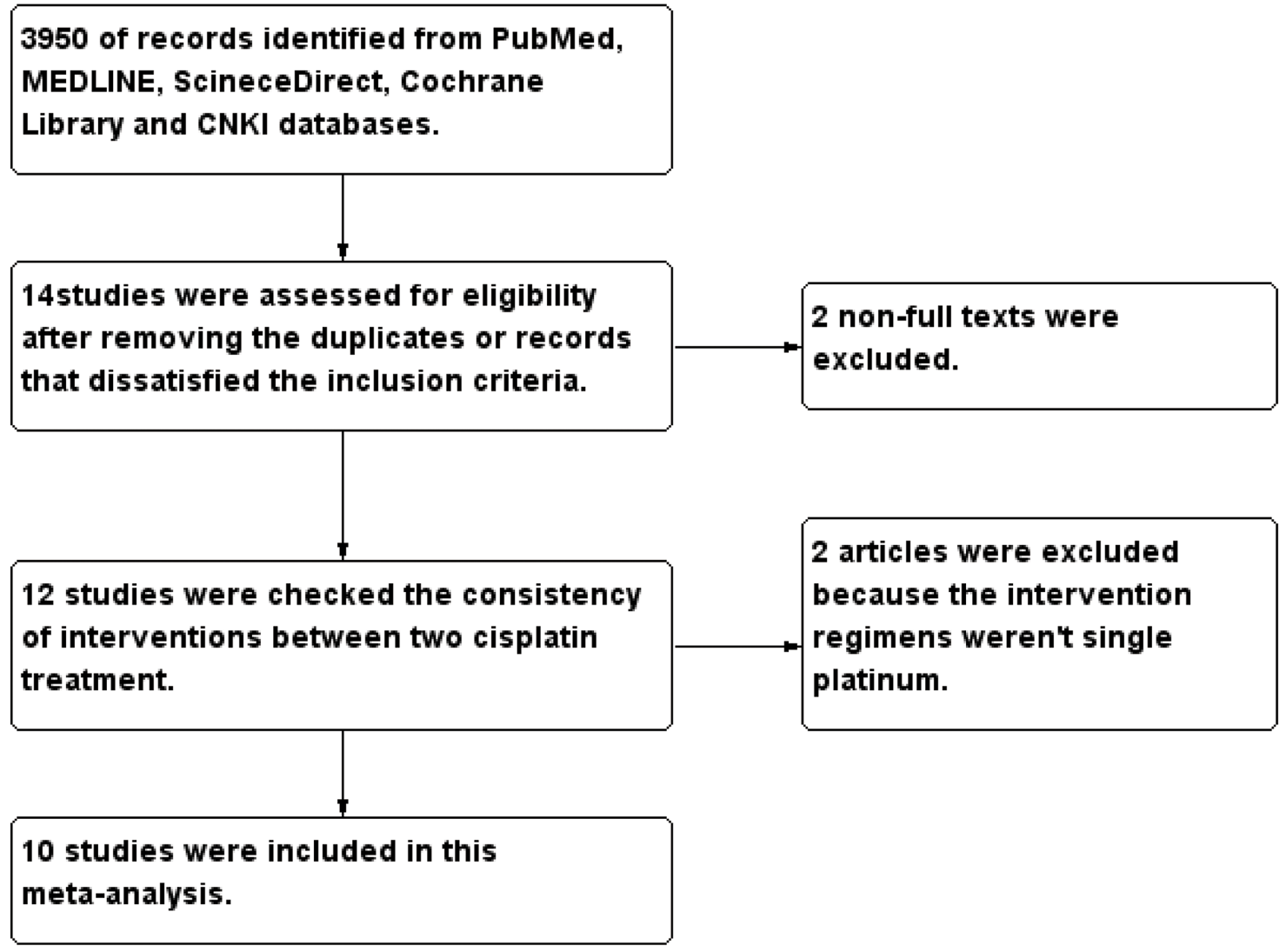

Figure 1: Study selection flow about the cisplatin-based chemoradiotherapy of head and neck cancer. $\mathrm{CNKI}=\mathrm{China}$ National Knowledge Infrastructure. 
Table 1: Summary of the included studies

\begin{tabular}{|c|c|c|c|c|c|c|c|c|}
\hline Author, year & Method & Country & Stage & N(Q1,Q3) & $\operatorname{Age}(Q 1, Q 3, y)$ & $\begin{array}{c}\operatorname{Sex}(Q 1: M / F ; \\
\text { Q3:M/F) }\end{array}$ & Chemotherapy & $\begin{array}{c}\text { Mean total } \\
\text { radiation } \\
\text { dose }\end{array}$ \\
\hline Geeta SN, 2006 & $\begin{array}{c}\text { Retro } \\
2004-05\end{array}$ & India & II-IV & $\begin{array}{l}32 \\
51\end{array}$ & $\begin{array}{c}57.5 \\
55\end{array}$ & $\begin{array}{c}\text { Q1:26/6 } \\
\text { Q3:37/14 }\end{array}$ & $\begin{array}{c}\mathrm{Q} 1: 40 \mathrm{mg} / \\
\mathrm{m}^{2}, 6 \text { cycles } \\
\mathrm{Q} 3: 100 \mathrm{mg} / \mathrm{m}^{2}, 2- \\
\text { 3days,3cycles }\end{array}$ & $\begin{array}{c}66-70 \mathrm{~Gy} \\
33-35 \mathrm{~F}\end{array}$ \\
\hline Но KF, 2008 & $\begin{array}{c}\text { Retro } \\
2000-04\end{array}$ & England & IVa & $\begin{array}{l}24 \\
27\end{array}$ & & & $\begin{array}{c}\mathrm{Q} 1: 33-40 \mathrm{mg} / \\
\mathrm{m}^{2}, 6 \text { cycles } \\
\mathrm{Q} 3: 80-100 \mathrm{mg} / \\
\mathrm{m}^{2}, 3 \text { cycles }\end{array}$ & $\begin{array}{c}\text { 60-70Gy } \\
33 \mathrm{~F}, 45 \text { days }\end{array}$ \\
\hline Huang DN, 2009 & $\begin{array}{c}\text { RCT } \\
\text { 2003-07 }\end{array}$ & China & III $\sim \mathrm{IVa}$ & $\begin{array}{l}33 \\
32\end{array}$ & $\begin{array}{l}43 \\
41\end{array}$ & $\begin{array}{c}\text { Q1:24/9 } \\
\text { Q3:20/12 }\end{array}$ & $\begin{array}{c}\text { QW:30mg/m²,7- } \\
\text { 8cycles } \\
\text { Q3W:80mg/ } \\
\mathrm{m}^{2}, 3 \text { cycles }\end{array}$ & $\begin{array}{c}\text { 50-76Gy } \\
2 \mathrm{~Gy} / \mathrm{F}, 5 \\
\text { days/week }\end{array}$ \\
\hline Uygun K, 2009 & $\begin{array}{c}\text { Retro } \\
2002-07\end{array}$ & Turkey & III-IV & $\begin{array}{l}20 \\
30\end{array}$ & $\begin{array}{c}71 \\
53.2\end{array}$ & & $\begin{array}{l}\text { Q1:40mg/ } \\
\mathrm{m}^{2}, 6 \text { cycles } \\
\text { Q3:100mg/ } \\
\mathrm{m}^{2}, 3 \text { cycles }\end{array}$ & $\begin{array}{c}\text { 66-70Gy } \\
\text { 33-35F,2Gy/ } \\
\text { day }\end{array}$ \\
\hline Kose F, 2011 & $\begin{array}{c}\text { Retro } \\
2007-09\end{array}$ & Turkey & II-IV & $\begin{array}{l}32 \\
23\end{array}$ & $\begin{array}{l}58 \\
60\end{array}$ & $\begin{array}{l}\text { Q1: 26/6; } \\
\text { Q3:18/5 }\end{array}$ & $\begin{array}{c}\text { Q1:30mg/m² } \\
\text { Q3:100mg/m² }\end{array}$ & $\begin{array}{l}\text { 50-70Gy } \\
\text { 2Gy/day, } \\
\text { 5days/week }\end{array}$ \\
\hline Tsan DL, 2012 & $\begin{array}{c}\text { RCT } \\
2008-10\end{array}$ & Taiwan & II-IV & $\begin{array}{l}24 \\
26\end{array}$ & $\begin{array}{c}49 \\
49.2\end{array}$ & $\begin{array}{l}\text { Q1:23/1 } \\
\text { Q3:25/1 }\end{array}$ & $\begin{array}{c}\text { Q1:40mg/m² } \\
\text { Q3:100mg/m² }\end{array}$ & $\begin{array}{c}\text { 66Gy } \\
2 \mathrm{~Gy} / \mathrm{F}, 5 \\
\text { days/week }\end{array}$ \\
\hline Espeli V, 2012 & $\begin{array}{c}\text { Retro } \\
2002-09\end{array}$ & Switzerland & I-IV & $\begin{array}{l}40 \\
54\end{array}$ & $\begin{array}{l}65 \\
58\end{array}$ & $\begin{array}{c}\text { Q1:32/8 } \\
\text { Q3:43/11 }\end{array}$ & $\begin{array}{c}\mathrm{Q} 1: 40 \mathrm{mg} / \\
\mathrm{m}^{2}, 6 \text { cycles } \\
\mathrm{Q} 3: 100 \mathrm{mg} / \mathrm{m}^{2}, \\
3 \text { cycles }\end{array}$ & 66-72Gy \\
\hline Jagdis A, 2014 & $\begin{array}{c}\text { Retro } \\
\text { 2000-09 }\end{array}$ & British & II-IVb & $\begin{array}{l}45 \\
28\end{array}$ & $\begin{array}{c}51 \\
49.5\end{array}$ & $\begin{array}{l}\text { Q1:35/10 } \\
\text { Q3:15/13 }\end{array}$ & $\begin{array}{l}\mathrm{Q} 1: 40 \mathrm{mg} / \mathrm{m}^{2} \\
\mathrm{Q} 3: 100 \mathrm{mg} / \\
\mathrm{m}^{2}, 3 \text { cycles }\end{array}$ & $\begin{array}{c}\text { 66-70Gy } \\
33-35 \mathrm{~F}\end{array}$ \\
\hline Geiger JL, 2014 & $\begin{array}{c}\text { Retro } \\
2004-10\end{array}$ & $\begin{array}{l}\text { United } \\
\text { States }\end{array}$ & III-IV & $\begin{array}{l}53 \\
51\end{array}$ & $\begin{array}{l}61 \\
53\end{array}$ & & $\begin{array}{c}\mathrm{Q} 1: 25-30 \mathrm{mg} / \mathrm{m}^{2} \\
\mathrm{Q} 3: 100 \mathrm{mg} / \\
\mathrm{m}^{2}, 3 \text { cycles }\end{array}$ & $\begin{array}{c}\text { 60-70Gy } \\
30-35 \mathrm{~F}\end{array}$ \\
\hline Тао CJ, 2014 & $\begin{array}{c}\text { Retro } \\
2003-07\end{array}$ & China & II-IVb & $\begin{array}{l}73 \\
81\end{array}$ & $\mathrm{P}=0.351$ & $\begin{array}{l}\text { Q1:56/17 } \\
\text { Q3:59/22 }\end{array}$ & $\begin{array}{c}\mathrm{Q} 1: 30-40 \mathrm{mg} / \mathrm{m}^{2}, 5- \\
7 \text { cycles } \\
\text { Q3:80mg/ } \\
\mathrm{m}^{2}, 3 \text { cycles }\end{array}$ & $\begin{array}{l}\text { 60-68Gy } \\
30 \mathrm{~F} \\
2.27 \mathrm{~Gy} / \mathrm{F}\end{array}$ \\
\hline
\end{tabular}

$\mathrm{RCT}=$ randomised controlled trial; Retro = retrospective comparative study; $\mathrm{Q} 1=$ weekly; $\mathrm{Q} 3=$ three weekly; $\mathrm{y}=\mathrm{year}$; $\mathrm{M}=$ male; $\mathrm{F}=$ female; $\mathrm{F}=$ fraction.

\section{Locoregional recurrence-free survival}

Three studies [6, 14-15] were included in the LRFS analysis, including 129 patients in weekly group and 130 patients in three weekly group. Forest plot showed no difference of 1- and 2-year LRFS between the weekly and three weekly cisplatin-based CCRT for $\mathrm{HNC}$ patients (1-year LRRFS: $\mathrm{HR}=1.26$, 95\% CI $0.46-3.46, p=0.65$; 2-year LRRFS: $\mathrm{HR}=1.14$, 95\%CI $0.51-2.56, p=0.74)$. Details were displayed in the Figure 3.

\section{Adverse effects}

Grade $\geq 3$ adverse effects were gathered from the enrolled studies, including hematologic toxicity (neutropenia, thrombocytopenia and anemia) and nonhematologic toxicity, including gastrointestinal toxicity, dermatitis, mucositis.

\section{Grade $\geq 3$ hematologic toxicity}

Six studies supplied data of grade $\geq 3$ neutropenia $[6,8,10-13]$ among which included 178 patients in the 


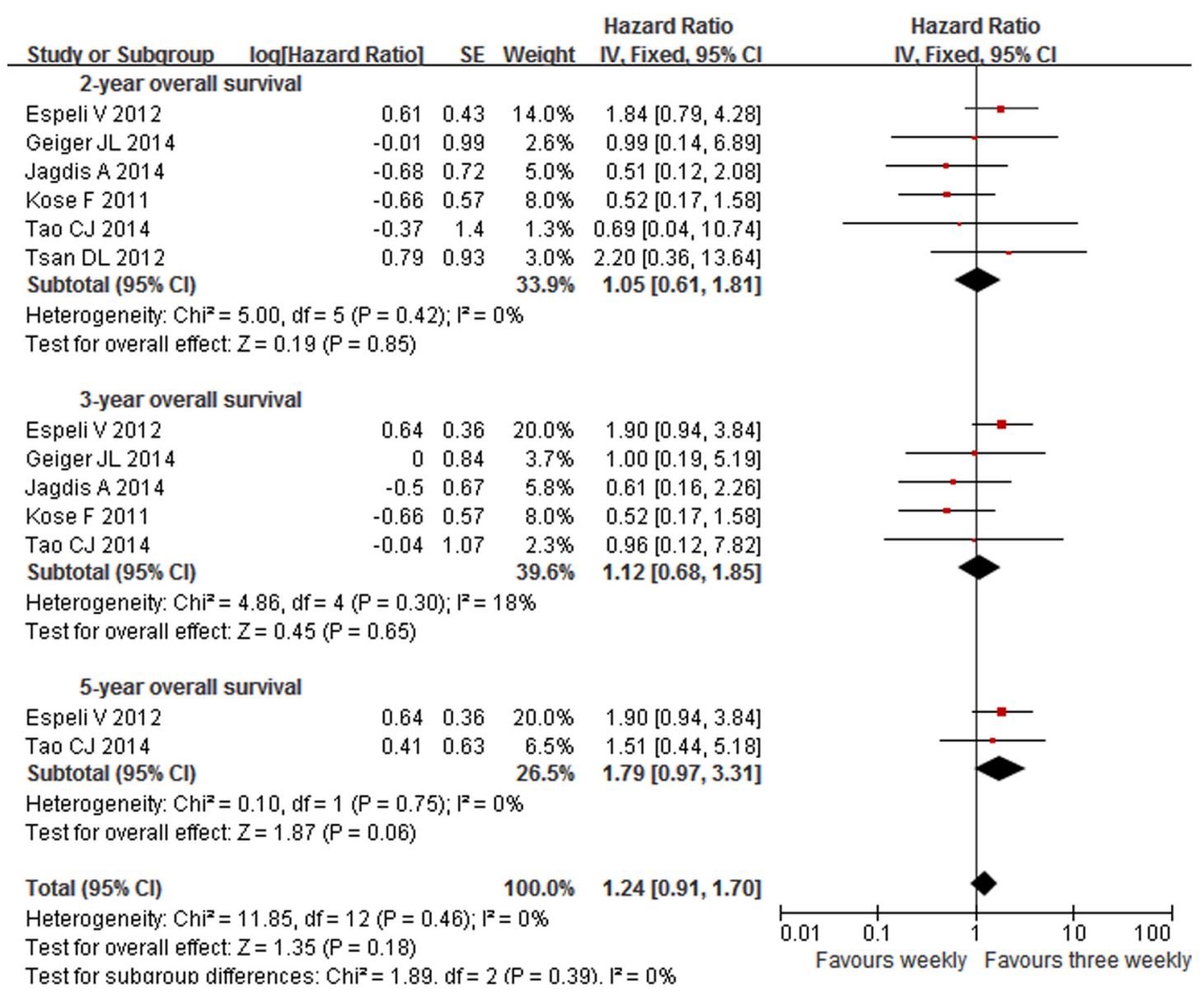

Figure 2: Forest plots of hazard ratios for 2-year, 3-year and 5-year OS in patients between weekly and three weekly cisplatin chemoradiotherapy. $\mathrm{OS}=$ overall survival. $\mathrm{CI}=$ confidence interval, $\mathrm{I} 2=$ index of heterogeneity.

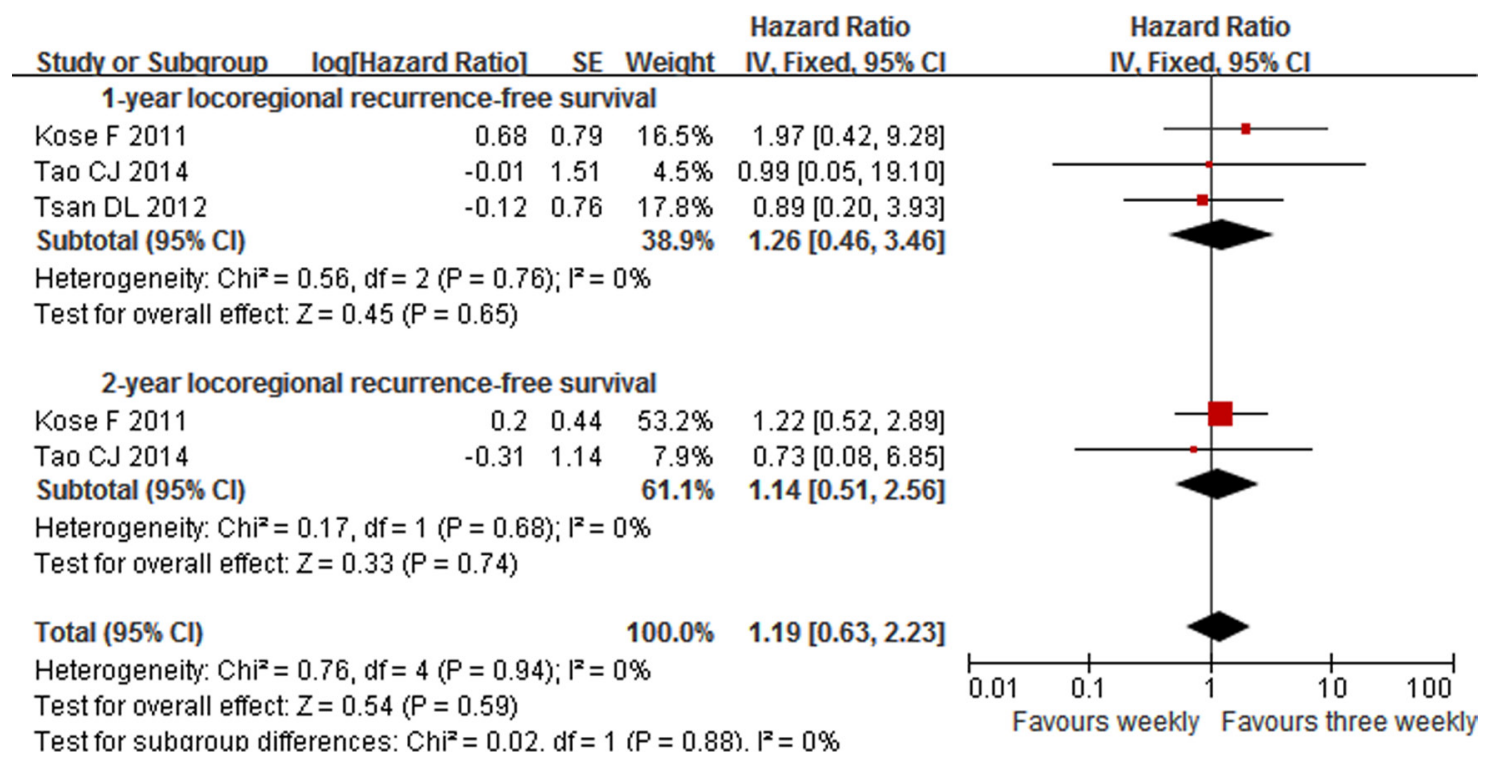

Figure 3: Forest plots of hazard ratios for 1-year and 2-year LRFS in patients between weekly and three weekly cisplatin chemoradiotherapy. LRFS=Locoregional recurrence-free survival. $\mathrm{CI}=$ confidence interval, $\mathrm{I}^{2}=$ index of heterogeneity. 
weekly group and 194 patients in the three weekly group. Forest plot showed that patients in the two arms had similar risk of neutropenia and thrombocytopenia with RR of 0.85 and 1.13 , respectively (95\%CI $0.49-1.48, \mathrm{p}=0.57$; 95\% CI 0.42-3.01, $\mathrm{p}=0.81$ ) (Supplementary Figure S1 and $\mathrm{S} 2$ ). But a trend of anemia risk reduction was observed in favor of the weekly arm with an RR of $2.88(95 \%$ CI $0.84-$ 9.94, $\mathrm{p}=0.09$ ) (Supplementary Figure S3).

\section{Grade $\geq 3$ gastrointestinal reactions}

Nausea and/or vomiting were the most common gastrointestinal reactions for patients treated with ciplatinbased CRT. The data of grade $\geq 3$ nausea/vomiting were extracted from six eligible studies [6, 10-13, 15] including 219 patients in weekly group and 224 patients in three weekly group. Patients treated with three weekly cisplatin seemed to be more prone to occur nausea and/or vomiting than those with weekly $(\mathrm{RR}=0.59,95 \% \mathrm{CI} \quad 0.34-1.02$, $\mathrm{p}=0.06$ ) (Supplementary Figure S4).

\section{Grade $\geq \mathbf{3}$ dermatitis}

Six eligible studies $[6,8-11,15]$ had the data for grade $\geq 3$ dermatitis, which included 213 patients in weekly group and 269 patients in three weekly group. The weekly arm appeared similar risk of dermatitis compared to three weekly arm, with an RR of 1.23 (95\%CI 0.84-1.82, $\mathrm{p}=0.29$ ) (Supplementary Figure S5). Five of these studies were non-NPC [6, 8-11] with 140 weekly patients and 188 three weekly patients, and there was no significant difference in the grade $\geq 3$ dermatitis between the two groups of non-NPC patients $(\mathrm{RR}=1.31,95 \% \mathrm{CI} 0.88-1.95$, $\mathrm{p}=0.18$ ). No heterogeneity was observed for dermatitis analysis.

\section{Grade $\geq 3$ mucositis}

Eight articles [6, 8-10, 12-15] of 624 patients reported the data of mucosal toxicity. No obvious difference was observed for the risk of grade $\geq 3$ mucositis between the two groups. Further analysis was performed based on the disease sites. Five studies of 332 non-NPC patients (148 weekly patients and 184 three weekly patients) and three studies of 292 NPC patients (151 weekly patients and 141 three weekly patients) were included. Subgroup analyses were much interesting that patients in weekly group suffered grade $\geq 3$ mucositis more easily when the primary disease located in nonnasopharynx $\quad(\mathrm{RR}=1.72,95 \% \mathrm{CI} \quad 1.13-2.61, \mathrm{p}=0.01)$ (Figure 4) with a not significant heterogeneity of $43 \%$ $(p=0.13)$. However, when the disease site arose in nasopharynx, patients of the two groups had similar risk $(\mathrm{RR}=0.65,95 \% \mathrm{CI} 0.29-1.45, \mathrm{p}=0.29)$.

\section{Treatment delays or interruption}

Many patients suffered serious adverse effects in the process of CRT, which often resulted in delay or interrupt of treatment. We calculated the chemotherapy completion for weekly (6-8cycles) and three weekly (3cycles) from six studies $[6,9-11,13,15]$ while the forest plot revealed a noticeable heterogeneity $\left(\mathrm{I}^{2}=59 \%, \mathrm{p}=0.03\right)$. After looking all eligible studies through, in Ho KF's study [11], there were almost $42 \%$ patients in weekly group and 30\% in three weekly group received cisplatin and 5-fluorouracil (PF) induction chemotherapy prior to concurrent CRT and the majority $(83 \%)$ received 2 cycles of neoadjuvant chemotherapy, which might be the source of heterogeneity.

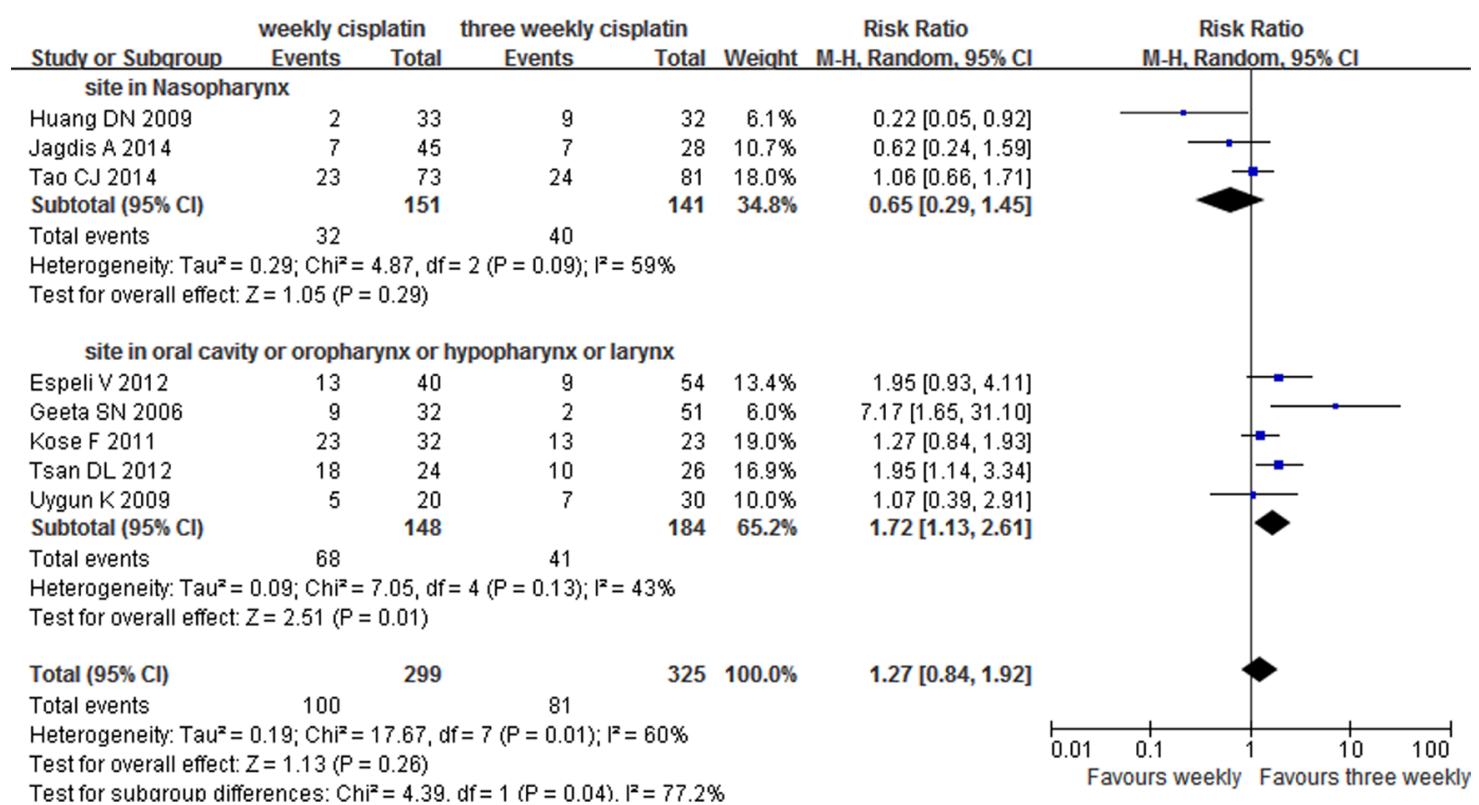

Figure 4: Weekly versus three weekly cisplatin chemoradiotherapy with toxicity grade $\geq 3$ mucositis. $\mathrm{CI}=$ confidence interval, $\mathrm{I}^{2}=$ index of heterogeneity. 
Therefore, Ho KF's study was removed from the forest analysis. Finally, five studies were enrolled with an acceptable heterogeneity $\left(\mathrm{I}^{2}=35 \%, \mathrm{p}=0.19\right)$. It is important to note that patients in weekly group suffered more chemotherapy delay/interrupt than three weekly patients $(\mathrm{RR}=2.68,95 \% \mathrm{CI} 1.65-4.35, \mathrm{p}<0.0001)$ (Figure 5).

\section{DISCUSSION}

Currently, there has been a significant increase in the global incidence of HNC and over half of patients were diagnosed with advanced disease at the initially visit [16]. Wee $\mathrm{J}$ et al had reported that the addition of three weekly CDDP CRT regimen manifested 2-and 3-year overall survival rates of $85 \%$ and $80 \%$, which was similar in the results of the Intergroup 00-99Trial with 2-year OS $82 \%$ and 3-year OS 78\% [17-18]. Simultaneously, another randomized trial of 350 patients by Chan et al using weekly CDDP at $40 \mathrm{mg} / \mathrm{m}^{2}$ during the RT showed a better 5-year OS rate when compared to RT only (CRT $70.3 \%$ versus RT $58.6 \%, \mathrm{p}=0.049$ ) at the end of follow up [19]. In our analysis, a trend of better 5-year OS was found in three weekly group when compared with weekly scheme, although the two groups had similar short-term survivals (2- and 3-OS). It is reported that patients with better local control possibly possessed better survivals [17]. Therefore, we hypothesized that three weekly cisplatin CRT might improve long-term OS due to a higher rate of locoregional control though the long-term data of LRFS were not available. On the other hand, data showed that a cumulative dose of $200 \mathrm{mg} / \mathrm{m}^{2}$ might lead to similar tumor control $[6,8]$, thereby, it was important to achieve such dose. But the courses were always interrupted or postponed in many patients as a result of adverse effects, especially for mucosal toxicity [20]. Similarly, our metaanalysis showed that patients in weekly cisplatin group had significant difficulty in achieving targeted dose of $200 \mathrm{mg} / \mathrm{m}^{2}(\mathrm{RR}=0.82, \mathrm{p}=0.009)$ (Supplementary Figure S6), eventually, resulting in a worse survival benefit due to more treatment delay/interrupt and inadequate dose of cisplatin [21-22]. There is an urgent need that a longer follow-up work and higher quality of clinical trials were performed to test the ideas.

Many studies have confirmed that cisplatin acted as a radiosensitizer and cisplatin-based concurrent CRT had more toxicity than radiotherapy alone on severe (grade 3 or higher) adverse effects, whether weekly $(\mathrm{p}<0.001)$ or three weekly cisplatin $(\mathrm{p}=0.001)$ was administrated [23$26]$. It was reported that up to $87 \%$ of patients treated with weekly cisplatin reached grade $\geq 3$ toxicity $[18,27]$ and $57 \%$ in three weekly group $[14,17,24,28]$.

One of the most serious adverse reactions is mucositis, which might be attributed to wide RT portal (extending from the skull base to the root of the neck) and significant doses of RT delivered to the mucosal surfaces due to bulky primary or cervical nodes [24]. In our study, no obvious difference was observed between the two treatments, however, subgroup analysis showed that patients with non-NPC occurred more grade $\geq 3$ mucositis when treated by weekly CRT. The reasons might be as follows: 1) More frequent administration of cisplatin. It had been reported that radiosensitization effect can be improved when with more frequent administration of cisplatin, thus, resulting in more severe mucositis [29]. Consensus opinion was supported by Tsan DL's trial. 2) The choice of hydration might account for some difference in mucosal toxicity. In a phase III randomized study, patients in three weekly group suffered significantly lower grade $\geq 3$ mucositis than weekly patients due to hydration before and after cisplatin infusion (three weekly ciaplatin vs. weekly cisplatin $=38.5 \%$ vs. $75 \%, p=0.012$ ) [6], which needed more trial to confirm further.

In terms of gastrointestinal effects, patients in three weekly cisplatin group tended to occur more nausea and/or vomiting than those in weekly group $(R R=0.59, p=0.06)$. While a phase II trial fractionated CDDP into four daily doses during the concurrent CRT to reduce the emesis rate and improved tolerability [17]. Same viewpoint was reached by other studies that spread out doses of cisplatin over several days might reduce the chemotherapy-induced gastrointestinal toxicity while still providing a beneficial antitumor effect as well $[2,6]$. Therefore, clinical trials that comparing weekly cisplatin with three weekly

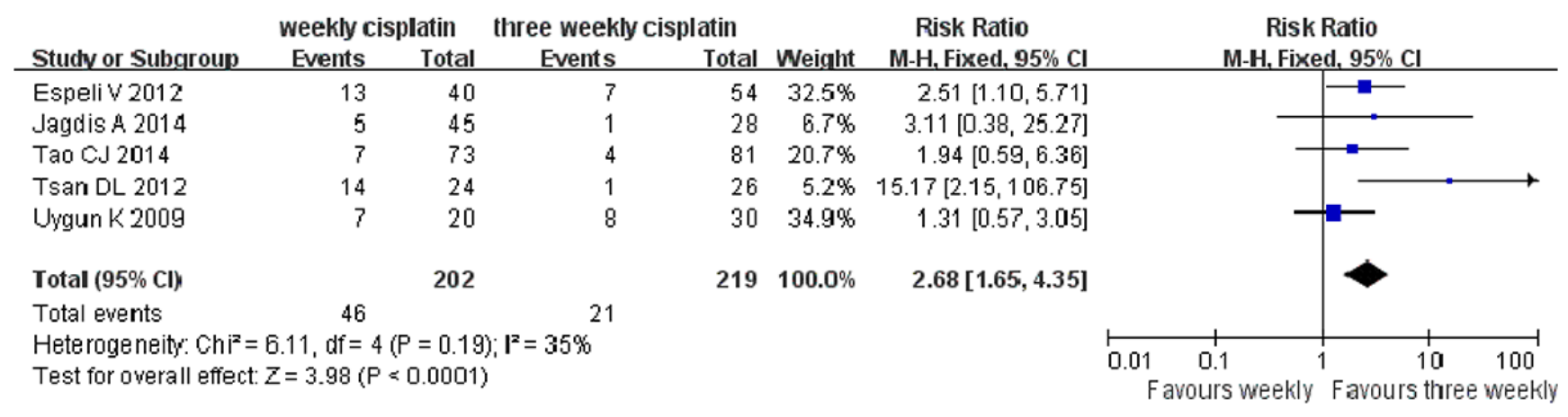

Figure 5: Weekly versus three weekly cisplatin chemoradiotherapy in delays or interruption of treatment. $\mathrm{CI}=$ confidence interval, $\mathrm{I}^{2}=$ index of heterogeneity. 
delivered moderately are urgently needed to reach a decision scientifically.

Kidney damage was also common adverse reaction during CRT [30]. Study reported that up to $53.7 \%$ of patients treated with three weekly cisplatin suffered acute renal failure compared $35 \%$ weekly patients despite no statistical significance $(p=0.07)$ [9]. Kose $\mathrm{F}$ et al had mentioned similar renal toxicity between the two different cisplatin regimens, even total cisplatin doses in three weekly group were higher than weekly group ( $210 \mathrm{mg} / \mathrm{m}^{2}$ vs. $\left.162 \mathrm{mg} / \mathrm{m}^{2}, \mathrm{p}<0.0001\right)$. Similar conclusion was supported by others [11-13]. One of eligible studies referred to liver toxicity [12], and only grade1 toxicity was observed with no significance between weekly $(0.3 \%)$ and three weekly cisplatin patients $(0.3 \%)$. However, we were unable to discuss these topics due to the inconsistent assessment methods and data deficiencies from enrolled studies.

Chemotherapy administration costs and drug acquisition costs were the most significant components of treatment for inpatients and outpatients [31]. Peter $\mathrm{G}$ had calculated the costs of administering weekly cisplatin-based regimen for per patient with cervical cancer (inpatient setting were $\$ 8839$ compared with $\$ 3590$ in the outpatient setting). And the total cost of three weekly cisplatin-based CRT was $\$ 3303$ for HNC patients [32]. Although no difference was reported for the mean radiotherapy overall treatment time $[6,11,13,15]$, the frequency of visiting doctors for weekly group participants tended to increase relatively. Hence, patients receiving three weekly cisplatin might be more comfortable during treatment with less administration costs.

Nevertheless, we had to mention several limitations in this study. Firstly, there were only two RCTs eligible, while the other eights were retrospective. Secondly, not all articles reported the data of OS, progression-free survival (PFS), LRFS, disease-free survival (DFS), especially the long-term survival data. Thirdly, we only analyzed the acute toxicities, whereas, chronic toxicities were not obtainable, such as xerostomia, dysphagia, hearing loss, radiation-induced brain injury and so on.

Taking together, weekly cisplatin CRT had no difference in overall survival but less comfort in treatment process compared with three weekly cisplatin regimen. It is important to proceed with a long-term follow-up of the chronic toxicities and survival events to explore which treatment could make patients benefit most. Kunieda F et al had launched a randomized phase II/III study in Japan [33], and we are looking forward to make further efforts for the research.

\section{MATERIALS AND METHODS}

\section{Search methods for identification of studies}

We performed a literature search in the PubMed, MEDLINE, ScineceDirect, Cochrane Library and CNKI databases published between 1982-2014. The key words were: "head and neck neoplasms" OR "head and neck cancer" OR "head and neck tumor" OR "head-neck tumors", "cisplatin" OR "Cis-platinum" OR "Platinol" OR "CDDP", "triweekly" OR "three weeks" OR "every three weeks", "per week" OR "every week" OR "weekly" OR "once a week" and "randomized controlled trial" OR "randomized control trials" OR "randomized clinical trial" OR "RCT" OR "randomly allocation" OR "randomly" OR "random" OR "controlled" OR "trial" OR. We also searched for "lip" "oral cavity" "oropharyngeal" "hypopharyngeal" "nasopharyngeal" "laryngeal" "sinus" "salivary gland", respectively. All of the eligible articles and their references were retrieved. We excluded reviews, case reports and animal experiments, moreover, meeting abstracts that had not been published full-text were also excluded. We would consider the studies as a single one if they had been published twice or more by the seam team and based on the same patient source.

\section{Data collection and analysis}

Following information were extracted from the included studies: first author, publication year, study design, treatment protocol, number of patients, staging information, acute adverse reactions and survival events. Two authors conducted the eligibility assessment and data verification independently. If agreement could not be reached between the two authors, a third author would participate in the discussion until reaching final agreement.

Endpoints were determined as overall survival, locoregional recurrence-free survival and adverse events. RevMan 5.2 software (Cochrane Collaboration's Information Management System) was used to perform this meta-analysis. Risk ratios of adverse effect were calculated with the correspondent $95 \%$ confidence interval (CI), in addition, time-to-event data from individual trials were summarized by the log hazard ratio (HR) and its variance. If the trials did not report survival information directly, Kaplan-Meier curves were read by the Engauge Digitizer version 4.1 (free software downloaded from http://sourceforge.net) and DerSimonian-Laird random effect analysis was used to estimate the difference. Subgroup analyses were conducted according to the range of follow-up times and lesion sites. Heterogeneity was assessed by forest plots, chi-squared $\left(\chi^{2}\right)$ tests and $\mathrm{I}^{2}$ statistic percentages. $\mathrm{P}$ values below 0.05 were defined as significant outcomes. Fixed-effect model was applied when homogeneity was fine ( $\left.\mathrm{p} \geq 0.10, \mathrm{I}^{2} \leq 50 \%\right)$, otherwise, a random-effect model was used.

\section{ACKNOWLEDGMENTS}

Preliminary abstract of this meta-analysis has been published in ASCO 2015 annual meeting as a poster presentation. Chicago, IL, May, 30, 2015. 


\section{CONFLICTS OF INTEREST}

There authors report no other conflicts of interest.

\section{REFERENCES}

1. Adelstein DJ, Li Y, Adams GL, Wagner H Jr, Kish JA, Ensley JF, Schuller DE, Forastiere AA. An intergroup phase III comparison of standard radiation therapy and two schedules of concurrent chemoradiotherapy in patients with unresectable squamous cell head and neck cancer. Journal of Clinical Oncology. 2003; 21:92-98.

2. NCCN Clinical Practice Guidelines in Oncology:Head and Neck Cancers, Version 1, 2015.

3. Pignon JP, le Maître A, Maillard E, Bourhis J, MACH-NC Collaborative Group. Meta-analysis of chemotherapy in head and neck cancer (MACH-NC): an update on 93 randomised trials and 17,346 patients. Radiotherapy and Oncology. 2009; 92:4-14.

4. Marcial VA, Pajak TF, Mohiuddin M, Cooper JS, al Sarraf M, Mowry PA, Curran W, Crissman J, Rodríguez M, Vélez-García E. Concomitant cisplatin chemotherapy and radiotherapy in advanced mucosal squamous cell carcinoma of the head and neck. Long-term results of the Radiation Therapy Oncology Group study 81-17. Cancer. 1990; 66:1861-1868.

5. Sharma A, Mohanti BK, Thakar A, Bahadur S, Bhasker S. Concomitant chemoradiation versus radical radiotherapy in advanced squamous cell carcinoma oforopharynx and nasopharynx using weekly cisplatin:a phase II randomized trial. Annals of Oncology. 2010; 21:2272-2277.

6. Tsan DL, Lin CY, Kang CJ, Huang SF, Fan KH, Liao CT, Chen IH, Lee LY, Wang HM, Chang JT. The comparison between weekly and three-weekly cisplatin delivered concurrently with radiotherapy for patients with postoperative high-risk squamous cell carcinoma of the oral cavity. Radiation Oncology. 2012; 7:215.

7. Geiger JL, Lazim AF, Walsh FJ, Foote RL, Moore EJ, Okuno SH, Olsen KD, Kasperbauer JL, Price DL, Garces YI, Ma DJ, Neben-Wittich MA, Molina JR, et al. Adjuvant chemoradiation therapy with high-dose versus weekly cisplatin for resected, locally-advanced HPV/ p16-positiveand negative head and neck squamous cell carcinoma. Oral oncology. 2014; 50:311-318.

8. Geeta SN, Padmanabhan TK, Samuel J, Pavithran K, Iyer $\mathrm{S}$, Kuriakose MA. Comparison of acute toxicities of two chemotherapy schedules for head and neck cancers. Journal of cancer research and therapeutics. 2006; 2:100-104.

9. Espelia V, Zuccaa E, Ghielminia M, Giannini O, Salatino A, Martucci F, Richetti A. Weekly and 3-weekly cisplatin concurrent with intensity-modulatedradiotherapy in locally advanced head and neck squamous cell cancer. Oral Oncology. 2012; 48:266-271.
10. Uygun K, Bilici A, Karagol H, Caloglu M, Cicin I, Aksu G, Fayda M, Uzunoglu S. The comparison of weekly and three-weekly cisplatin chemotherapy concurrent with radiotherapy in patients with previously untreated inoperable non-metastatic squamous cell carcinoma of the head and neck. Cancer chemotherapy and pharmacology. 2009; 64:601-605.

11. Ho KF, Swindell R, Brammer CV. Dose intensity comparison between weekly and 3-weekly Cisplatindelivered concurrently with radical radiotherapy for head and neckcancer: A retrospective comparison from New Cross Hospital, Wolverhampton, UK. Acta Oncologica. 2008; 47:1513-1518.

12. Huang DN, Huang HX, Chen SJ, Li GS. Different Administration Regimens of Cisplatin Combined withConcurrent Radiotherapy for 65 Cases with Locally AdvancedNasopharyngeal Carcinoma. Journal of Oncology. 2009; 15:836-838.

13. Jagdis A, Laskin J, Hao D, Hay J, Wu J, Ho C. Dose Delivery Analysis of Weekly Versus 3-Weekly CisplatinConcurrent With Radiation Therapy for Locally AdvancedNasopharyngeal Carcinoma (NPC). American Journal of Clinical Oncology. 2014; 37:63-69.

14. Kose F, Besen A, Sumbul T, Sezer A, Karadeniz C, Disel U, Altundag O, Ozyilkan O. Weekly Cisplatin versus Standard Three-weekly Cisplatin in Concurrent Chemoradiotherapy of Head and Neck Cancer: the Baskent University Experience. Asian Pacific Journal of Cancer Prevention. 2011; 12:1185-1188.

15. Tao CJ, Lin L, Zhou GQ, Tang LL, Chen L, Mao YP, Zeng MS, Kang TB, Jia WH, Shao JY, Mai HQ, Lin AH, Ma J, Sun Y. Comparison of long-term survival and toxicity of cisplatin delivered weekly versus every three weeks concurrently with intensity-modulated radiotherapy in nasopharyngeal carcinoma. PLoS One. 2014; 9:e110765.

16. Kawecki A, Krajewski R. Follow-up in patients treated for head and neck cancer. Magazine of European medical oncology. 2014; 7:87-91.

17. Wee J, Tan EH, Tai BC, Wong HB, Leong SS, Tan T, Chua ET, Yang E, Lee KM, Fong KW, Tan HS, Lee KS, Loong S, et al. Randomized Trial of Radiotherapy Versus Concurrent Chemoradiotherapy Followed by Adjuvant Chemotherapy in Patients With American Joint Committee on Cancer/ International Union Against Cancer Stage III and IV Nasopharyngeal Cancer of the Endemic Variety. Journal of clinical oncology. 2005; 23:6730-6738.

18. Al-Sarraf M, LeBlanc M, Giri PG, Fu KK, Cooper J, Vuong T, Forastiere AA, Adams G, Sakr WA, Schuller DE, Ensley JF. Chemoradiotherapy versus radiotherapy in patients with advanced nasopharyngeal cancer: Phase III randomized Intergroup study 0099. Journal of clinical oncology. 1998; 16:1310-1317. 
19. Chan AT1, Leung SF, Ngan RK, Teo PM, Lau WH, Kwan WH, Hui EP, Yiu HY, Yeo W, Cheung FY, Yu KH, Chiu $\mathrm{KW}$, Chan DT, et al. Overall survival after concurrent cisplatin-radiotherapy compared with radiotherapy alone in locoregionally advanced nasopharyngeal carcinoma. Journal of the National Cancer Institute. 2005; 97:536-539.

20. Allal AS, de Pree C, Dulguerov P, Bieri S, Maire D, Kurtz JM. Avoidance of treatment interruption: an unrecognized benefit of accelerated RT in Oropharyngeal carcinoma? International journal of radiation oncology, biology, physics. 1999; 45:41-45.

21. Ou X, Zhou X, Shi Q, Xing X, Yang Y, Xu T, Shen C, Wang X, He X, Kong L, Ying H, Hu C. Treatment outcomes and late toxicities of 869 patients with nasopharyngeal carcinoma treated with definitive intensity modulated radiation therapy: new insight into the value of total dose of cisplatin and radiation boost. Oncotarget 2015; 6:3838138397. doi: 10.18632/oncotarget.5420.

22. Gasparini G, Pozza F, Recher G, Panizzoni GA, Cristoferi V, Squaquara R, Dal Fior S. Simultaneous cisplatin and RT in inoperable or locally advanced squamous cell carcinoma of the head and neck. Oncology 1991; 48:270-276.

23. Quon H, Leong T, Haselow R, Leipzig B, Cooper J, Forastiere A. Phase III study of radiation therapy with or without cis-platinum in patients with unresectable squamous or undifferentiated carcinoma of the head and neck: an intergroup trial of the Eastern Cooperative Oncology Group (E2382). International journal of radiation oncology, biology, physics. 2011; 81:719-725.

24. Bernier J, Domenge C, Ozsahin M, Matuszewska K, Lefèbvre JL, Greiner RH, Giralt J, Maingon P, Rolland F, Bolla M, Cognetti F, Bourhis J, Kirkpatrick A, et al. Postoperative irradiation with or without concomitant chemotherapy for locally advanced head and neck cancer. The New England journal of medicine. 2004; 350:1945-1952.

25. Begg AC. Cisplatin and radiation: interaction probabilities and therapeutic possibilities International journal of radiation oncology, biology, physics. 1990; 19:1183-1189.

26. Sharma VM, Wilson WR. Radiosensitization of advanced squamous cell carcinoma of the head and neck with cisplatinduring concomitant radiation therapy. European archives of oto-rhino-laryngology. 1999; 256:462-465.
27. Harrison LB, Pfister DG, Fass DE, Armstrong JG, Sessions RB, Shah JP, Spiro RH, Strong EW, Weisen S, Bosl GJ. Concomitant CT-radiation therapy followed by hyperfractionated radiation therapy for advanced unresectable head and neck cancer. International journal of radiation oncology, biology, physics. 1991; 21:703-708.

28. Cooper JS, Pajak TF, Forastiere AA, Jacobs J, Campbell BH, Saxman SB, Kish JA, Kim HE, Cmelak AJ, Rotman M, Machtay M, Ensley JF, Chao KS, et al. Postoperative concurrent radiotherapy and chemotherapy for high-risk squamous-cell carcinoma of the head and neck. The New England journal of medicine. 2004; 350:1937-1944.

29. Marcu L, Bezak E, Olver I. Scheduling cisplatin and radiotherapy in the treatment of squamous cell carcinomas of the head and neck: a modelling approach. Physics in medicine and biology. 2006; 51:3625-3637.

30. Driessen CM, Uijen MJ, van der Graaf WT, van Opstal CC, Kaanders JH, Nijenhuis T, van Herpen CM. Degree of nephrotoxicity after intermediate- or high-dose cisplatinbased chemoradiotherapy in patients with locally advanced head and neck cancer. Head \& neck. 2015; doi: 10.1002/ hed.24281.

31. Rose PG, Lappas PT. Analysis of the cost effectiveness of concurrent cisplatin-based chemoradiation in cervical cancer: implications from five randomized trials. Gynecologic oncology. 2000; 78:3-6.

32. Brentani A, de Castro G Jr, Federico MH. Cost-effectiveness analysis of cisplatin-based chemoradiation to treat patients with unresectable, nonmetastatic head and neck cancer in Brazil. Head and neck. 2011; 33:1199-1205.

33. Kunieda F, Kiyota N, Tahara M, Kodaira T, Hayashi R, Ishikura S, Mizusawa J, Nakamura K, Fukuda H, Fujii M. Head and Neck Cancer Study Group of the Japan Clinical Oncology Group. Randomized phase II/III trial of postoperative chemoradiotherapy comparing 3-weekly cisplatin with weekly cisplatin in high-risk patients with squamous cell carcinoma of head and neck: Japan Clinical Oncology Group Study (JCOG1008). Japanese journal of clinical oncology. 2014; 44:770-774. 